Gut, 1988, 29, 631-635

\title{
Cisapride restores the decreased lower oesophageal sphincter pressure in reflux patients
}

\author{
P CECCATELLI, J JANSSENS, G VANTRAPPEN, AND S CUCCHIARA
}

From the Division of Gastroenterology, Department of Medicine and Medical Research, University of Leuven, Leuven, Belgium

SUMMARY The effect of the new prokinetic drug cisapride on the resting lower oesophageal sphincter pressure and on the strength of peristaltic contractions was studied in $\mathbf{1 0}$ healthy controls and in 10 reflux patients with abnormally low $(<10 \mathrm{~mm} \mathrm{Hg})$ basal lower oesophageal sphincter pressure. A slow intravenous injection of cisapride $10 \mathrm{mg}$ significantly increased the sphincter pressure in the controls but even more in the patients in whom it almost doubled the resting lower oesophageal sphincter pressure of $8 \cdot 7(0.5) \mathrm{mm} \mathrm{Hg}$ to between 15 and $20 \mathrm{~mm} \mathrm{Hg}$ for at least $90 \mathrm{~min}$. Results are expressed as mean (SE). Cisapride also significantly increased the amplitude of peristaltic contractions in controls and reflux patients. Therefore, cisapride might be useful in the treatment of reflux.

It is well known that a decreased lower oesophageal sphincter (LOS) pressure and an impaired oesophageal clearance are important factors in the pathogenesis of reflux disease. ${ }^{1-9}$ Therefore, various motor stimulating drugs such as bethanechol, metoclopramide and domperidone, which may increase LOS tone and/or the efficiency of oesophageal peristaltic contractions, have been proposed for the treatment of gastro-oesophageal reflux disease. ${ }^{10-16}$ Bethanechol and metoclopramide, however, may have significant side effects, while domperidone hardly increases LOS pressure in reflux patients. Cisapride is a novel gastrointestinal prokinetic drug, devoid of antidopaminergic and direct cholinergic effects acting mainly by the release of acetylcholine at the myenteric plexus site. ${ }^{17}$ The present study examined in a double blind, crossover manner the effect of cisapride (versus placebo) on lower oesophageal sphincter pressure and oesophageal peristalsis in normal controls and in patients with reflux symptoms and an abnormally low basal LOS pressure.

Address for correspondence: Professor G Vantrappen, MD, PhD, Head Department of Medicine and Division of Gastroenterology, University Hospital Gasthuisberg, University of Leuven, Leuven, Belgium.

Received for publication 2 November 1987.

\section{Methods}

PATIENTS AND SUBJECTS

Studies were undertaken in 10 subjects (six men, aged 22 to 61 years; mean age 45) complaining of typical symptoms of gastro-oesophageal reflux, who were selected on the basis of a mean maximal LOS pressure of less than $10 \mathrm{~mm} \mathrm{Hg}(1 \mathrm{~mm} \mathrm{Hg}=133 \mathrm{~Pa})$. Ten healthy volunteers without any digestive symptoms were studied as a control group (eight men; aged 21-35 years; mean age 26). Informed consent was obtained from each subject. The protocol for this study was approved by the Ethical Committee of the Medical Faculty of the University of Leuven.

Oesophageal manometry was performed with a catheter assembly, $5 \mathrm{~mm}$ in diameter and consisting of seven polyvinyl chloride catheters $(0.8 \mathrm{~mm}$ ID; 1.5 $\mathrm{mm}$ OD), connected to external transducers (E 0333E - E154E; Siemens, Elema, Sweden). Pressures were recorded on an eight channel polygraph (Mingograph 82, Siemens). All catheters were continuously perfused with distilled water through a low compliance capillary tube infusion pump (Arndorfer Medical Specialists, Greendale, Wis, USA) at a rate of $0.6 \mathrm{ml} / \mathrm{min}$. The four distal 
recording orifices were located at the same level but were oriented in four different radial directions, $90^{\circ}$ apart. The three other catheters were spaced at $5 \mathrm{~cm}$ intervals. The catheter assembly was passed through the nose. Deglutitions were signalled by means of a cutaneous EMG electrode placed over the region of the suprahyoid muscle.

Lower oesophageal sphincter pressure was measured by a stationary pull through technique $(0.5$ $\mathrm{cm}$ increment per step). The highest mean pressure of the four radially oriented orifices was taken as the LOS pressure. Oesophageal body motility was evaluated at 5,10 , and $15 \mathrm{~cm}$ above the LOS after wet swallows ( $5 \mathrm{ml}$ water). The amplitude, duration and progression velocity of the deglutitive peristaltic contractions were expressed as the mean value of five consecutive swallows but also as a mean value for the three levels (5-10-15 cm above LOS). Amplitude $(\mathrm{mm} \mathrm{Hg})$ of the contraction was measured from baseline to peak; duration (sec) was measured as the time between onset and end of the pressure peaks determined by the intersection of the extrapolation of the wave at the highest slope with the baseline; progression velocity $(\mathrm{cm} / \mathrm{sec})$ of the peristaltic wave was calculated from the time laps between the onset of the pressure peak at $15 \mathrm{~cm}$ and at $5 \mathrm{~cm}$ above the LOS.

Studies were carried out after an overnight fast. The study design was of the double blind crossover type. On two different days, and in a random order, each subject received a slow intravenous injection of $10 \mathrm{mg}$ cisapride or placebo. Values for mean LOS pressure and for the different parameters of the contraction waves were determined every $15 \mathrm{~min}$, starting $30 \mathrm{~min}$ before and lasting until $90 \mathrm{~min}$ after drug administration. The results for the two periods ( $-30 \mathrm{~min}$ and $-15 \mathrm{~min}$ ) before drug administration were pooled and considered as the basal values. Manometric tracings were coded and evaluated blindly. Results were expressed as mean (SE).

For statistical evaluation, the results in the two crossover groups were first subjected to Koch's analysis of a two period change over design, which is valid even if assumptions on the normality and variance homogeneity may not apply. ${ }^{18}$ This method uses the Mann-Whitney U-test and tests the equality of period, residual or treatment effects. The analysis of the results showed that no statistically significant period or residual effects occurred, thus warranting combination of the data obtained during respectively the two cisapride and the two placebo phases. The merged data were subsequently subjected to the Student's paired $t$ test for evaluation of intratreatment changes in the various parameters $v$ the preinjection period, and differences in these changes with cisapride and placebo.
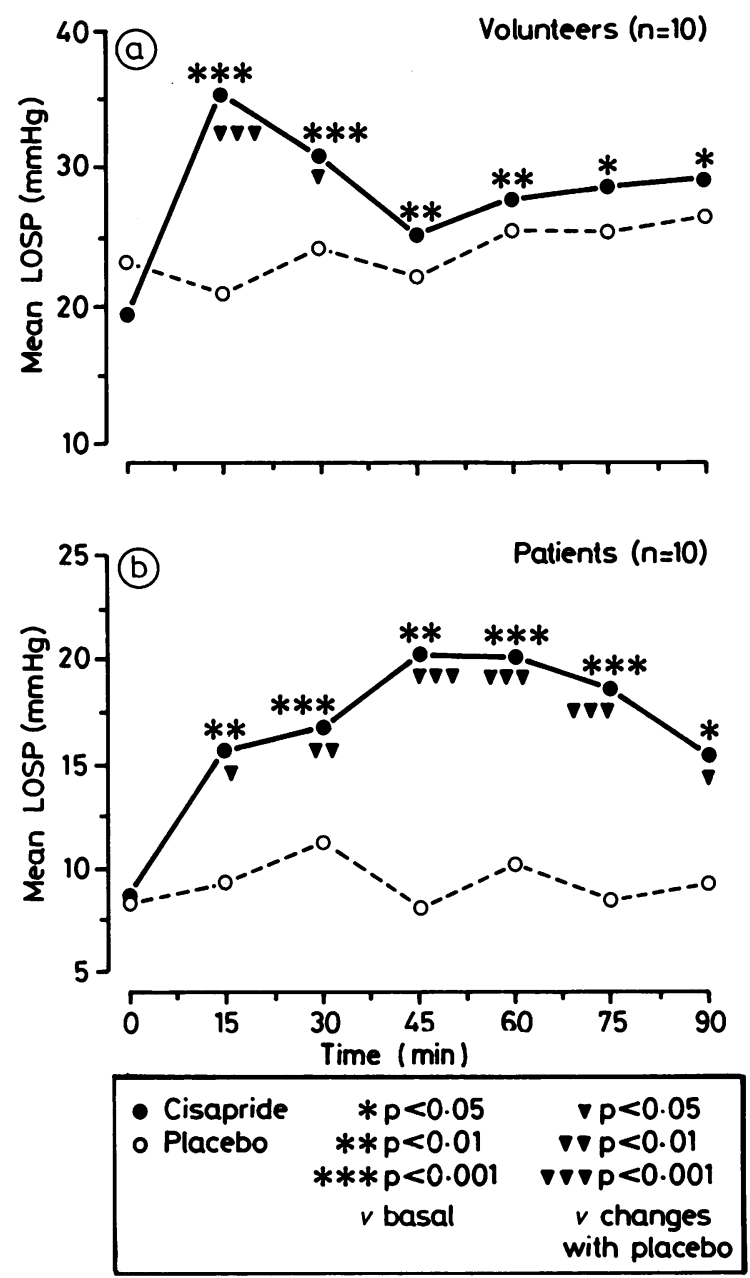

Fig. 1 Effect of cisapride on resting LOS pressure in normal volunteers (Fig. 1a) and in reflux patients with a low basal LOS pressure - that is, less than $10 \mathrm{~mm} \mathrm{Hg}$ (1 $\mathrm{mm} \mathrm{Hg=133} \mathrm{Pa)} \mathrm{(Fig.} 1 \mathrm{~b})$.

\section{Results}

\section{LOS PRESSURE}

The mean basal LOS pressure was $19.3(1.0) \mathrm{mm} \mathrm{Hg}$ in the control subjects and $8.7(0.5) \mathrm{mm} \mathrm{Hg}$ in the reflux patients. No significant change in LOS pressure was noticed after placebo, either in the controls or in the reflux patients. Cisapride induced a significant ( $v$ basal values and $v$ placebo) rise in LOS pressure in both the controls and the patients. In the control subjects the LOS pressure increased to a peak value of $34.2(2.8) \mathrm{mm} \mathrm{Hg}$ at $15 \mathrm{~min}$ after drug administration [\% change: $+90 \%(20 \%)$ ] (Fig. 1a). In the reflux patients with low basal LOS pressure the 

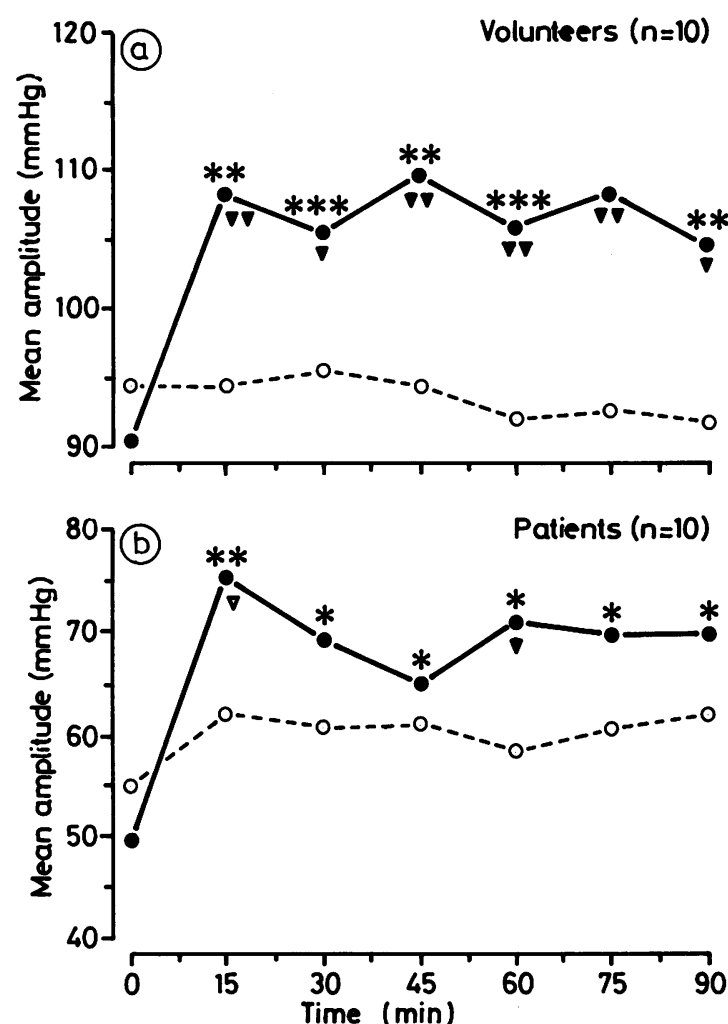

\begin{tabular}{|ccc|}
\hline - Cisapride & $* p<0.05$ & $v p<0.05$ \\
0 Placebo & $* * p<0.01$ & $v p<0.01$ \\
& $* * * p<0.001$ & $v>p<0.001$ \\
& $v$ basal & $\begin{array}{c}v \text { changes } \\
\text { with placebo }\end{array}$ \\
\hline
\end{tabular}

Fig. 2 Effect of cisapride on amplitude of peristaltic oesophageal body contractions in normal volunteers (Fig. $2 a)$ and in reflux patients with a low basal LOS pressure-that is, less than $10 \mathrm{~mm} \mathrm{Hg}(1 \mathrm{~mm} \mathrm{Hg}=133 \mathrm{~Pa})$ (Fig. 2b).

effect of cisapride was even more pronounced: LOS pressure began to rise within the first 15 min period, reached a peak value of $20.35(2.3) \mathrm{mm} \mathrm{Hg}$ at $45 \mathrm{~min}$ after drug administration [\% change: $+145 \%(37 \%)$ ] and remained significantly increased throughout the 90-min study period ( $\mathrm{p}<0.05-0.001)$ (Fig. 1b).

\section{OESOPHAGEAL PERISTALSIS}

The administration of placebo had no significant effect upon amplitude, duration, and progression velocity of the deglutitive peristaltic contractions.

After cisapride, however, a significant ( $v$ basal values and $v$ placebo) increase in amplitude of the peristaltic contractions was observed in the control subjects and in the patients with reflux disease. In the control group, the mean amplitude significantly increased throughout the $90 \mathrm{~min}$ registration period from $90.5(9.8) \mathrm{mm} \mathrm{Hg}$ during the basal period to a maximum mean value of $109.59(12.40) \mathrm{mm} \mathrm{Hg} 45$ min after drug administration [\% change: $21 \%(2 \%)$ ] (Fig. 2a). In the reflux patients, the increase in amplitude was even more pronounced, from 49.7 (5.0) $\mathrm{mm} \mathrm{Hg}$ during the basal period to a maximum mean value of $75.4(8.8) \mathrm{mm} \mathrm{Hg} 15 \mathrm{~min}$ after drug administration [\% change: $+47 \%(8 \%)$ ] (Fig. 2b) and remained significantly increased throughout the 90 min period.

After cisapride, there was a trend for the duration of the contraction waves to increase and for their progression velocity to decrease, but these effects did not reach statistical significancy. No side effects were observed after the administration of cisapride.

\section{Discussion}

The results of the present study clearly show that cisapride, administered iv in a dose of $10 \mathrm{mg}$, increases the resting LOS pressure not only in normal controls but also in reflux patients with an abnormally low resting LOS pressure. Cisapride also significantly increased the amplitude of the peristaltic oesophageal body contractions. Therefore, cisapride might be useful in the treatment of reflux disease.

As shown by Dodds et $a l^{6}$ gastro-oesophageal reflux can occur by one of the three following mechanisms: (a) a transient complete relaxation of the LOS, (b) a transient increase in intra-abdominal pressure, and (c) spontaneous reflux associated with low resting LOS pressure. Although there is considerable overlap in mean resting LOS pressure between reflux patients and normals, abnormally low values of basal LOS pressure are almost always associated with severe reflux. ${ }^{21920}$ Once reflux has occurred, the bulk of the refluxed material is cleared from the oesophageal lumen by primary peristaltic contractions whereas the minimal residual acid is neutralised by the swallowed saliva. ${ }^{9}$ In normal subjects, the amplitude of the peristaltic contraction is not the critical factor for acid clearing because any contraction amplitude within the broad range of normal is sufficient to obliterate the oesophageal lumen and strip all fluid from the oesophagus. ${ }^{8}$ As oesophageal peristalsis is frequently impaired in patients with reflux disease, however, ${ }^{21-25}$ and as oesophageal emptying is impaired in patients with reflux symptoms who have oesophageal motor dysfunction, ${ }^{7}$ it is possible that the decrease in amplitude of oesophageal contractions in reflux patients contributes to the disability of the oesophagus to clear the refluxed material.

To increase LOS strength and to improve the 
peristaltic performance of the oesophagus, motor stimulating drugs have been used in the treatment of reflux disease. Bethanechol has been shown to increase the resting LOS pressure and to improve oesophageal acid clearing in patients with reflux. ${ }^{10-11}$ Metoclopramide also increases LOS pressure in normal subjects and in reflux patients ${ }^{13-14}$ but its ability to increase oesophageal clearing awaits further documentation. Both drugs, however, may have considerable side effects. Domperidone has less side effects but hardly increases LOS pressure in reflux patients. ${ }^{1516}$

Cisapride is a novel gastrointestinal prokinetic drug, devoid of antidopaminergic and direct cholinergic effects, acting mainly by facilitating the release of acetylcholine at the myenteric plexus site. ${ }^{24}$ Cisapride has been shown to increase LOS pressure and the amplitude of the oesophageal body contractions in normal controls ${ }^{26-31}$ and in patients with reflux disease, ${ }^{32}$ but it has never been shown thus far whether cisapride is also able to increase LOS pressure in reflux patients with an abnormally low resting LOS pressure.

Our study clearly shows that a slow intravenous injection of $10 \mathrm{mg}$ of cisapride is able to increase the abnormally low sphincter pressure $[8.7(0.5) \mathrm{mm} \mathrm{Hg}]$ to a more normal level of 15 to $20 \mathrm{~mm} \mathrm{Hg}$ for at least 90 minutes. It seems logical to accept that this increase may have a beneficial effect for the prevention of reflux in these patients. To what extent the increase in amplitude of the deglutitive peristaltic contractions may contribute to a better oesophageal clearance is less well understood.

We did not correlate the effect of cisapride on the LOS pressure with the different phases of the migrating motor complex (MMC). This does not invalidate the results obtained, however, because the mixing in our study of the values of LOS pressure during different phases of the MMC could only have resulted in an increase in the standard deviation of the measured values, thus making it more difficult to reach statistical significancy. Although the results of our studies present indirect evidence for a potentially beneficial effect of the drug in reflux disease, longterm controlled trials have to be carried out to fully assess the therapeutic value of cisapride in the treatment of patients with gastro-oesophageal reflux. Preliminary experience in oesophagitis patients suggests that cisapride is superior to placebo in reducing reflux symptoms and healing oesophageal mucosal lesions. ${ }^{33}$

\section{References}

1 Pope CE. A dynamic test of sphincter strength: its application to lower esophageal sphincter pressure. Gastroenterology 1967; 52: 779-86.
2 Haddad JK. Relation of gastroesophageal reflux to yield sphincter pressures. Gastroenterology 1970; 58: 175-84.

3 Ahtaridis G, Snape WJ, Cohen S. Lower esophageal sphincter pressure as an index of gastroesophageal acid reflux. Dig Dis Sci 1981; 26: 993-8.

4 Welch RW, Lackmann K, Racks P, Drake ST, Bannayan G, Owensby L. Lower esophageal sphincter pressure in histologic esophagitis. Dig Dis Sci 1980; 25: 420-6.

5 Richter JE, Castell DO. Gastroesophageal reflux. Ann Intern Med 1982; 97: 93-103.

6 Dodds WJ, Dent J, Hogan WJ, et al. Mechanism of gastroesophageal reflux in patients with reflux esophagitis. N Engl J Med 1982; 307: 1547-52.

7 Tolin RD, Malmud LS, Reilley J, Fisher R. Esophageal scintigraphy to quantitate esophageal transit (quantitation of esophageal transit). Gastroenterology 1979; 76: 1402-8.

8 Helm JF, Dodds WJ, Riedel DR, Teeter BC, Hogan WJ, Arndorfer RC. Determinants of esophageal acid clearance in normal subjects. Gastroenterology 1983; 85: 607-12.

9 Helm J, Dodds WJ, Pelc LR, Palmer DW, Hogan WJ, Teeter BC. Effect of esophageal emptying and saliva on clearance of acid from the esophagus. $N$ Engl J Med 1984; 310: 284-8.

10 Farrell RL, Roling GT, Castell DO. Stimulation of the incompetent lower esophageal sphincter: a possible advantage in therapy of heartburn. Am J Dig Dis 1973; 18: $646-50$.

11 Miller WN, Ganeshappa KP, Dodds WJ, Hogan WJ, Barreras RR, Arndorfer RC. Effect of bethanechol on gastroesophageal reflux. Am J Dig Dis 1977; 22: 230-4.

12 Heitmann P, Möller N. The effect of metoclopramide on the gastro-esophageal junctional zone and the distal esophagus in man. Scand J Gastroenterol 1970; 5: 620-6.

13 Dilawari JB, Misiewicz JJ. Action of metoclopramide on the gastroesophageal junction of man. Gut 1973; 14: 380-2.

14 McCallum RW, Kline MM, Curry N, Sturdevant RAL. Comparative effects of metoclopramide and bethanechol on lower esophageal sphincter pressure in reflux patients. Gastroenterology 1975; 68: 1114-8.

15 Blackwell JN, Heading RC, Fettes MR. Effects of domperidone on lower oesophageal sphincter pressure and gastrooesophageal reflux in patients with peptic oesophagitis. In: Towse G, ed. Progress with domperidone, a gastrokinetic and anti-emetic agent. London: Academic Press, 1981: 57-61.

16 Pozzese C, Materia E, Corazziari E, Anzini F. Effects of domperidone on oesophageal motor activity and gastrooesophageal reflux. Ital J Gastroenterol 1982; 14: 159-61.

17 Schuurkes JAJ, Van Nueten JM, Van Daele PGH, Reyntjens AJ, Janssen PAJ. Motor-stimulating properties of cisapride on isolated gastrointestinal preparations of the guinea pig. J Pharmacol Exp Ther 1985; 234: 775-83.

18 Koch CG. The use of non-parametric methods in the statistical analysis of the two-period change-over design. Biometrics 1972; 28: 577-84.

19 Miller WN, Hogan WJ, Dodds WJ, Arndorfer RC, Ster 
JJ. A comprehensive investigation of patients with symptoms of gastroesophageal reflux (GER). Gastroenterology 1974; 66: 747.

20 Knuff TE, Benjamin SB, Worsham GF, Hancock JE, Castell DO. Histologic evaluation of chronic gastroesophageal reflux. Dig Dis Sci 1984; 29: 194-201.

21 Olsen AM, Schlegel JF. Motility disturbances caused by esophagitis. J Thorac Cardiovasc Surg 1965; 50: 607-12.

22 Affolter $H$. Pressure characteristics of reflux esophagitis. Helv Med Acta 1966; 33: 395-402.

23 Dodds WJ, Hogan WJ, Miller WN. Reflux esophagitis. Dig Dis Sci 1979; 21: 49-67.

24 Russell $\mathrm{COH}$, Pope CE, Gannon RM, Allen FD, Velasco N, Hill LD. Does surgery correct esophageal motor dysfunction in gastroesophageal reflux. Ann Surg 1981; 194: 290-6.

25 Heddle R, Dent J, Toouli J, Lewis I. Esophageal peristaltic dysfunction in peptic esophagitis [Abstract]. Gastroenterology 1984; 86: 1109.

26 Case WG, Williams NS. The effects of cisapride upon lower oesophageal sphincter pressure (LOSP) and primary peristalsis (PP). Dig Dis Sci 1986; 31: 465S.

27 Gilbert RJ, Dodds WJ, Kahrilas PJ, Hogan WJ, Lipman S. Double-blind assessment of the effect of intravenous and oral cisapride on esophageal motor function. Digestion 1986; 34: 139.

28 Smout AJPM, Bogaard JW, Grade AC, TenTheye OJ, Akkermans LM, Wittebol P. Effects of cisapride, a new gastrointestinal prokinetic substance, on interdigestive and postprandial motor activity of the distal esophagus in man. Gut 1986; 26: 246-51.

29 Wallin L, Kruse-Andersen S, Madsen T, Boesby S. Effect of cisapride on gastro-oesophageal function in normal human subjects. Digestion 1987; 37: 160.

30 Wienbeck M, Cuder-Wiesinger E, Berges W. Comparative study of cisapride's versus metoclopramide's effect on esophageal motility. Digestion 1986; 34: 141.

31 Weiser $\mathrm{H}$, Hölscher A, Zimmerman T. Effects of cisapride and metoclopramide on the lower esophageal motility. A pressure and $\mathrm{pH}$ metric study. Digestion 1986; 34: 142.

32 Corazziari E, Bontempo I, Anzini F. Effect of cisapride (C) on primary peristalsis and lower oesophageal sphincter (LOS) pressure [Abstract]. Gut 1984; 25: A1318.

33 Lepoutre L, Vanderlinden I, Bollen G, Vandewalle N, Cabooter M, Laukens $P$. Double-blind placebocontrolled study of cisapride in the treatment of grade II and III oesophagitis. Acta Clin Belg 1986; 41: 366. 